\title{
Medical thoracoscopic lung biopsy in interstitial lung disease: a prospective study of biopsy quality
}

\author{
J. Vansteenkiste*, E. Verbeken**, M. Thomeer*, P. Van Haecke*, A.V. Eeckhout*, M. Demedts*
}

Medical thoracoscopic lung biopsy in interstitial lung disease: a prospective study of biopsy quality. J. Vansteenkiste, E. Verbeken, M. Thomeer, P. Van Haecke, A.V. Eeckhout, M. Demedts. C) ERS Journals Ltd 1999.

ABSTRACT: The aim of this study was to analyse the quality and diagnostic value of lung biopsies for the diagnosis of interstitial lung disease (ILD), taken with diathermy coagulation cup forceps during medical thoracoscopy.

Patients with ILD, not specified after thorough clinical assessment, high-resolution CT (HRCT), bronchoalveolar lavage and transbronchial biopsy, were studied. Medical thoracoscopy was performed in an endoscopy suite under neuroleptic anaesthesia with spontaneous ventilation. Biopsy specimens were analysed prospectively by one lung pathologist blinded to the clinical findings.

Over 2 yrs, 118 samples were analysed from 24 consecutive patients. A good quality biopsy was obtained in 23 patients, and $78 \%$ of the samples were of good quality. Biopsy findings plus clinical and HRCT data revealed a relevant diagnosis in 18 patients and some diagnostic clues in four patients, for whom further examinations were needed. No major complications occurred. Chest tube drainage averaged 5.3 \pm 4.7 days, and was related to the total lung capacity $(\mathrm{p}=\mathbf{0 . 0 0 8})$, which mirrors the severity of ILD. Separate sampling of biopsies from different lobes proved to be useful in one third of the cases.

In conclusion, lung biopsy sampling can be performed safely by interventional pulmonary endoscopists and has a good diagnostic yield in interstitial lung disease of unknown origin.

Eur Respir J 1999; 14: 585-590.
*Dept of Pulmonary Medicine **Dept. of Pathology, University Hospital Gasthuisberg, Catholic University Leuven, Belgium

Correspondence: J. Vansteenkiste, Dept of Pulmonology, University Hospital Gasthuisberg, Herestraat 49, B-3000 Leuven, Belgium, Fax: 3216346803

Keywords: Interstitial lung disease interventional endoscopy

lung biopsy

medical thoracoscopy

minimally invasive techniques

prospective studies

Received: August 221998

Accepted after revision April 201999

Presented in part at the 1997 Berlin meeting of the European Respiratory Society
Thoracoscopy is important in the diagnosis of pleural disease and for pleurodesis in recurrent pneumothorax or pleural effusion. It has been safely and successfully performed by well trained pulmonologists for several decades [1, $2]$. The introduction of modern video equipment and more refined instrumentation expanded the indications, both for interventional pulmonary endoscopists performing video-assisted medical thoracoscopy (VAMT) [3-5] and thoracic surgeons performing video-assisted thoracoscopic surgery (VATS) [6, 7].

Interstitial lung disease (ILD) in the nonimmunocompromised patient is often a difficult challenge for the clinician, especially when no diagnostic clues are present after a thorough clinical assessment (could the disease be environmental or drug-induced?), laboratory examination including serology for specific connective tissue disease, chest radiography and high-resolution computed tomography (HRCT). Bronchoalveolar lavage (BAL) and transbronchial biopsy (TBB) are usually the next step [8]. TBB readily yields a diagnosis of sarcoidosis or carcinomatous lymphangitis, while a certain diagnosis from BAL fluid is possible in cases such as alveolar proteinosis and histiocytosis $\mathrm{X}$. In other conditions, results are often nonspecific, and an open lung biopsy (OLB) has long been the gold standard in the diagnosis of entities such as idiopathic pulmonary fibrosis (IPF).

Despite encouraging reports in the literature from the 1980 for medical thoracoscopy with lung biopsy (MTLB) in the diagnosis of interstitial lung disease in the nonimmunocompromised patient $[9,10]$, this technique gained little popularity amongst pulmonologists. More recently, North-American studies focused on the role of VATS in this setting, and nonrandomized comparisons of OLB versus VATS lung biopsy were reported $[11,12]$. No significant difference in the specimen volume obtained, complication rate, length of pleural drainage and duration of hospital stay were noted, although the VATS approach proved to be more expensive in one study [11].

Previous studies on VAMT with lung biopsy did not specifically focus on biopsy size and quality. Therefore, a prospective study was started to examine the latter characteristics in tissue samples obtained during VAMT in the diagnostic work-up of unspecified ILD.

\section{Patients and methods}

\section{Patients}

The procedure was introduced in the author's endoscopy unit in March 1995. Data of all patients referred for this technique over a period of 2 yrs were prospectively registered. Patients had proven or suspected ILD, not otherwise specified after a thorough clinical assessment, laboratory examination including specific serology for connective tissue disease and precipitating antigens, chest radiography and HRCT, pulmonary function tests (PFTs), BAL and TBB. The procedure was contra-indicated in patients with one of the following findings: coagulation deficit (prothrombin level $<50 \%$ or platelet count $<70,000$ cells $\cdot \mathrm{mm}^{-3}$ ); severe respiratory insufficiency (arterial carbon dioxide 


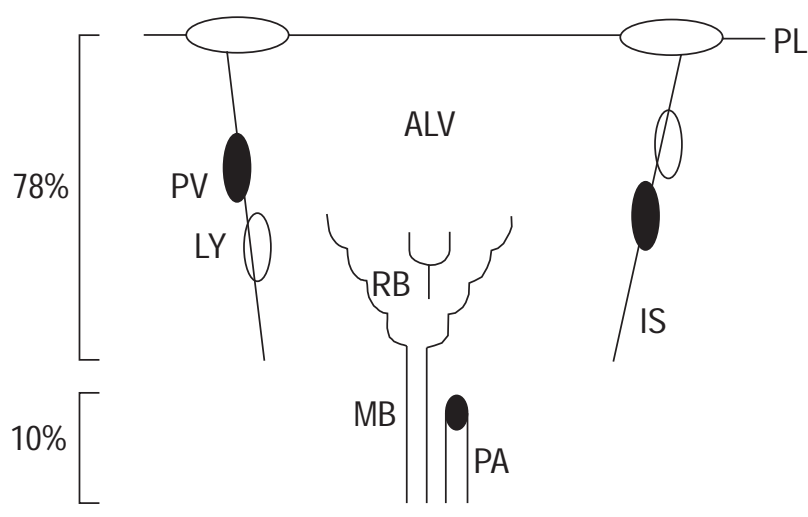

Fig. 1. - Schematic drawing of the anatomy of the secondary lobule is supplied by a bronchovascular bundle with a membranous bronchiole (MB) and a pulmonary artery (PA). The MB branches into respiratory bronchioles (RB) in the centrilobular area. At the end is the alveolated parenchyma (ALV) with precapillary arterioles. The lobule is surrounded by pleura (PL) and interlobular septa (IS) containing pulmonary veins (PV) and lymphatics (LY), the latter also being present in the bronchovascular bundle. During the medical thoracoscopy with lung biopsy procedure, the bronchovascular bundle is sampled in $10 \%$ of the specimens, and the periphery of the lobule, the IS and the PL in $78 \%$.

tension $\left(P \mathrm{a}, \mathrm{CO}_{2}\right)>8 \mathrm{kPa}(>60 \mathrm{mmHg})$; mechanical ventilation; radiological signs suggesting important pleural adhesions or major bullous degeneration of the lung.

\section{Procedure}

The procedure was carried out according to the method described by Boutin and coworkers $[13,14]$. Briefly, the patient was in lateral decubitus, and neuroleptic anaesthesia (Propofol (Zeneca) and Alfentanyl (JannsenCilag)) with spontaneous ventilation during the procedure used. A pneumothorax was induced by the introduction of $\sim 600 \mathrm{~mL}$ of air into the pleural space through a smooth ended pleural needle under pleural pressure control with the Kuss pneumothorax apparatus. After local anaesthesia with $2 \%$ lidocaine, a $10-\mathrm{mm}$ incision, usually in the 4 th or 5 th intercostal space on the midaxillary line, was made. After blunt dissection of the intercostal space, a 7-mm trocar (Wolf ${ }^{\mathrm{R}}$; Richard Wolf, Knittlingen, Germany) was inserted. The pleural cavity was explored and the aspect of the lung surface recorded. The cup biopsy forceps (Wolf) were passed through a second $5 \mathrm{~mm}$ insulated trocar (Wolf). The cup biopsy forceps were dipped in the lung parenchyma in an open position, then closed, and a lung sample taken while applying short pulses of diathermy coagulation. Usually, 6-10 biopsies were taken from different lobes. In case of an abnormal lung surface, biopsies were taken in and adjacent to abnormal areas. Finally, a chest tube was inserted to allow lung expansion. A pleural drainage with $-15 \mathrm{cmH}_{2} \mathrm{O}$ suction was maintained until the lung was fully expanded. Thorax drainage by a water-sealed drainage system or a Heimlich valve was used until the air-leak ceased.

\section{Pathology}

All biopsy samples were examined prospectively and blinded to the clinical data by one lung pathologist (EV), who recorded the number of biopsies from the upper and lower lobe respectively, and the maximal cross-sectional diameter of each biopsy. The degree of coagulation artefacts was rated as none, slight $(\leq 25 \%)$ or severe $(>25 \%)$.

The presence or absence of the major lobular components was noted (fig. 1); in the centre of the lobule: membranous bronchioles and accompanying pulmonary arteries; at the periphery of the lobule: the pleura and interlobular septa; in between the alveolated parenchyma with alveolar lumina, alveolar septa or interstitium, and the small precapillary arterioles.

Finally, an overall subjective quality score (good, intermediate, poor) was made for every biopsy, summarizing the degree of coagulation, the preservation of lung architecture and the presence or absence of the above mentioned tissue components.

\section{Final diagnosis}

For this purpose, the clinical disease classification adapted from CRYSTAL et al. [15] and the histopathological classification of KATZENSTEIN et al. [16] were used. The diagnostic yield was expressed in four categories: $1=$ specific diagnosis possible based solely on the biopsy material (e.g. carcinomatous lymphangitis); 2=biopsy material potentially diagnostic if supported with the clinical/HRCT findings (e.g. usual interstitial pneumonia); $3=$ biopsy material suggesting a group of diseases (e.g. lymphoid interstitial pneumonitis); and $4=0$ of no diagnostic value.

\section{Statistics}

Descriptive statistics were expressed as mean \pm SD. Factors related to the length of the air-leak after the procedure were analysed with univariate correlation.

\section{Results}

During the period from March 1995 to March 1997, a total of 37 procedures for ILD were carried out in the hospital. Eight patients had a thoracotomy with OLB and five had a VATS with a wedge biopsy by stapler. The 24 consecutive patients, who had MTLB in the same time interval, are the subject of this report.

There were 11 males and 13 females with a mean \pm SD (range) age of $52.3 \pm 16.7 \mathrm{yrs}(26-78)$. None of the patients had a coagulation disorder. PFTs were expressed as percentages of expected normal values. The mean \pm SD (range) of the forced vital capacity (FVC) was $88 \pm 18 \%$ (56-132), forced expiratory volume in one second (FEV1) $81 \pm 14 \%$ (54-109), total lung capacity (TLC) $85 \pm 16 \%$ (64-129), and diffusing capacity for carbon monoxide (DL,CO) $53 \pm 21 \%$ (28-94). Arterial oxygen tension $\left(\mathrm{Pa}_{\mathrm{a}} \mathrm{O}_{2}\right)$ was $9.8 \pm 2.7 \mathrm{kPa}(4.9-17)$, and $P_{\mathrm{a}}, \mathrm{CO}_{2} 5.0 \pm 0.9 \mathrm{kPa}(4-8)$. Static compliance was available in nine patients and was $44 \pm 24 \%$ of normal (12-78). Mean pulmonary artery pressure $(P$ pa $)$ was known in six patients, and was $34 \pm 6$ mmHg (24-43). Radiological abnormalities on chest radiography and HRCT were diffuse in eight patients, predominant in the upper part in two patients and in the lower part in 14. A previous BAL yielded nonspecific results in 17 patients and TBB in 11 . Five patients had been previously treated with corticosteroids. 
Table 1. - Thoracoscopy and biopsy findings, final diagnosis and follow-up data of the 24 study patients

\begin{tabular}{|c|c|c|c|c|c|c|c|}
\hline \multirow[b]{2}{*}{$\begin{array}{l}\mathrm{Pt} \\
\text { No. }\end{array}$} & \multicolumn{3}{|c|}{ Thoracoscopy } & \multicolumn{2}{|r|}{ Biopsy } & \multirow{2}{*}{ Final diagnosis ${ }^{\#}$} & \multirow{2}{*}{ Follow-up } \\
\hline & Macro & Guid* & Comp & $\begin{array}{l}\text { Size } \\
\mathrm{mm}^{+}\end{array}$ & Findings & & \\
\hline 1 & Gran & + & - & 2.5 & P. carinii pneumonia & Idem & Died; no autopsy \\
\hline 2 & NS & - & Air leak & $3.4^{\S}$ & $\begin{array}{l}\text { Specific sarcoidosis } \\
\text { granulomas }\end{array}$ & Idem & Uneventful; stable PFTs \\
\hline 3 & Gran & + & Bleeding & 3.9 & $\begin{array}{l}\text { Absence carcinomatous } \\
\text { lymphangitis }\end{array}$ & Idem & Confirmed at thoracotomy \\
\hline 4 & NS & - & - & $3.6^{\S}$ & $\begin{array}{l}\text { Carcinomatous lymphan- } \\
\text { gitis }\end{array}$ & Idem & $\begin{array}{l}\text { Remission with breast } \\
\text { cancer chemotherapy }\end{array}$ \\
\hline 5 & NS & - & - & 3.9 & $\mathrm{HP}$ & Idem & $\begin{array}{l}\text { Uneventful after exposure } \\
\text { to parrots stopped }\end{array}$ \\
\hline 6 & Gran & + & - & 6.0 & Amyloidosis & Idem & $\begin{array}{l}\text { Stable with iododoxoru- } \\
\text { bicin and PSCT }\end{array}$ \\
\hline 7 & NS & - & - & 3.6 & Healed OB & Idiopathic BOOP & $\begin{array}{l}\text { Uneventful; stable PFTs } \\
\text { at } 8 \mathrm{mo}\end{array}$ \\
\hline 8 & NS & - & - & 3.6 & $\begin{array}{l}\text { Intimal fibrosis of small } \\
\text { pulm. arteries }\end{array}$ & PPH & $\begin{array}{l}\text { Stable PFTs with antico- } \\
\text { agulation at } 36 \text { mo }\end{array}$ \\
\hline 9 & Nod & + & Air-leak & 2.1 & Compatible with CIP & Idiopathic UIP & $\begin{array}{l}\text { Slow decrease PFTs } \\
\text { despite steroids at } 33 \mathrm{mo}\end{array}$ \\
\hline 10 & Nod & + & - & $2.2^{\S}$ & Acute IP (Hamman-Rich) & Idem & Died; autopsy confirmed \\
\hline 11 & Nod & + & Fever & 3.6 & End-stage fibrosis & End-stage fibrosis & $\begin{array}{l}\text { Uneventful; stable PFTs } \\
\text { at } 26 \mathrm{mo}\end{array}$ \\
\hline 12 & Nod & + & - & 2.9 & CIP usual type & Idiopathic UIP & $\begin{array}{l}\text { Slow decrease PFTs } \\
\text { despite steroids at } 26 \text { mo }\end{array}$ \\
\hline 13 & NS & - & Air-leak & $3.4^{\S}$ & CIP usual type & Idiopathic UIP & Died; autopsy confirmed \\
\hline 14 & NS & - & - & 3.6 & CIP desq. type & Desq. IP & $\begin{array}{l}\text { Stable PFTs with azathio- } \\
\text { prine at } 22 \text { mo }\end{array}$ \\
\hline 15 & NS & - & Air-leak & 3.6 & Compatible with CIP & Idiopathic UIP & $\begin{array}{l}\text { Decrease PFTs despite } \\
\text { cycloph. at } 16 \text { mo }\end{array}$ \\
\hline 16 & Nod & + & Air-leak & 6.6 & Fibrinohaemorrhagic gran. & Wegener's disease & $\begin{array}{l}\text { Stable PFTs with cycloph. } \\
\text { at } 8 \text { mo }\end{array}$ \\
\hline 17 & NS & + & - & $6.0^{\S}$ & End-stage fibrosis & End-stage fibrosis & $\begin{array}{l}\text { Uneventful; stable PFTs } \\
\text { at } 11 \mathrm{mo}\end{array}$ \\
\hline 18 & NS & - & - & 5.9 & CIP desq. type & Desq. IP & $\begin{array}{l}\text { Slow decrease PFTs despite } \\
\text { steroids at } 12 \text { mo }\end{array}$ \\
\hline 19 & NS & + & - & 4.7 & $\begin{array}{l}\text { Chronic lymphoplasmoc. } \\
\text { IP }\end{array}$ & (Idiopathic LIP) & $\begin{array}{l}\text { Uneventful stable PFTs } \\
\text { at } 6 \text { mo }\end{array}$ \\
\hline 20 & NS & - & - & 3.9 & $\begin{array}{l}\text { Chronic lymphoplasmoc. } \\
\text { IP }\end{array}$ & (Idiopathic LIP) & Died; no autopsy \\
\hline 21 & NS & + & Air-leak & 5.1 & $\begin{array}{l}\text { Thrombotic type pulm. } \\
\text { hypertension }\end{array}$ & (Pulm. vascular problem) & $\begin{array}{l}\text { Scintigraphy: pulmonary } \\
\text { emboli }\end{array}$ \\
\hline 22 & Nod & + & Air-leak & 4.8 & Alveolar bleeding & (Pulm. vascular problem) & $\begin{array}{l}\text { Renal biopsy: Wegener's } \\
\text { disease }\end{array}$ \\
\hline 23 & NS & - & Fever & 2.9 & Normal lung parenchyma & (Absence of ILD) & $\begin{array}{l}\text { Uneventful; stable PFTs } \\
\text { at } 4 \text { mo }\end{array}$ \\
\hline 24 & Nod & + & Fever & 3.0 & No diagnostic findings & (Presumed idiop. UIP) & $\begin{array}{l}\text { Stable PFTs with azathio- } \\
\text { prine at } 14 \text { mo }\end{array}$ \\
\hline
\end{tabular}

$*_{:}^{+}$, macroscopy useful in the choice of the biopsy place; - , not useful ${ }^{+}:$maximal diameter of the biopsy, per patient; ${ }^{*}:$ correlated with clinical/computed tomography findings (the final diagnoses shown in parentheses are unclear and require further study); ${ }^{\S}:$ separate sampling of upper and lower lobe significant. Macro: macroscopic; Guid: guidance; Comp: complication; Gran: granulomatous; NS: nonspecific; Nod: nodular; BOOP: bronchiolitis obliterans organising pneumonia; PPH: primary pulmonary hypertension; UIP: usual interstitial pneumonia; LIP: lymphocytic interstitial pneumonia; HP: hy-persensitivity pneumonitis; OB: obliterative bronchiolitis; PSCT: peripheral stem cell transplantation; PFTs: pulmonary function tests; mo: months; CIP: chronic interstitial pneumonia; IP: interstitial pneumonia; desq.: desquamous; pulm.: pulmonary; idiop.: idiopathic; cycloph.: cyclophosphamide; P. carinii: Pneumocystic carinii.

\section{Procedure}

Characteristics of the procedure are summarized in table 1. The macroscopic aspect was normal or nonspecific in 14 patients, granulomatous with white and reddish areas in three patients, and nodular with a cobblestone aspect, thickened septa and blebs in seven. In five patients, pleural adhesions had to be treated with diathermy section before a satisfying inspection of the lung and pleural cavity was feasible. In 13 procedures, the choice of the biopsy site was guided by the direct thoracoscopic view, while in the other procedures, HRCT images were used to choose the biopsy areas. The mean $\pm \mathrm{SD}$ (range) number of biopsies per patient was $6.5 \pm 2.3(3-10)$. No major complications such as important bleeding or persistent bronchopleural fistula requiring thoracotomy, nor temporary respiratory insufficiency requiring mechanical ventilation, occurred. Low grade fever was noted in three patients and minor bleeding in one. Prolonged air-leak 
Table 2. - Quality of the biopsies and presence of different tissue components, per biopsy and per patient

\begin{tabular}{|c|c|c|c|c|}
\hline & \multicolumn{2}{|c|}{ Biopsies $(n=118)$} & \multicolumn{2}{|c|}{ Patients $(n=24)$} \\
\hline & $\mathrm{n}$ & $\%$ & $\mathrm{n}$ & $\%$ \\
\hline \multicolumn{5}{|c|}{ Quality of the specimen } \\
\hline Good & 92 & 78 & 23 & 96 \\
\hline Intermediate & 16 & 14 & 1 & 4 \\
\hline Poor & 10 & 8 & 0 & 0 \\
\hline \multicolumn{5}{|c|}{ Coagulation artifacts } \\
\hline None & 74 & 63 & 20 & 83 \\
\hline Slight & 28 & 23 & 3 & 13 \\
\hline Severe & 16 & 14 & 1 & 4 \\
\hline \multicolumn{5}{|c|}{ Pleura/interlobular septa } \\
\hline Present & 92 & 78 & 24 & 100 \\
\hline Absent & 26 & 22 & 0 & 0 \\
\hline \multicolumn{5}{|c|}{$\begin{array}{l}\text { Alveolated parenchyma/ } \\
\text { intestitium }\end{array}$} \\
\hline Present & 92 & 78 & 24 & 100 \\
\hline Absent & 26 & 22 & 0 & 0 \\
\hline \multicolumn{5}{|c|}{ Precapillary arterioles } \\
\hline Present & 64 & 54 & 21 & 88 \\
\hline Absent & 54 & 46 & 3 & 12 \\
\hline \multicolumn{5}{|c|}{$\begin{array}{l}\text { Membranous bronchioles/ } \\
\text { pulm. arteries }\end{array}$} \\
\hline Present & 12 & 10 & 10 & 42 \\
\hline Absent & 106 & 90 & 14 & 58 \\
\hline
\end{tabular}

(i.e. $>7$ days) was present in seven patients. The mean $\pm \mathrm{SD}$ (range) duration of pleural drainage was $5.3 \pm 4.7$ days $(0-$ 14). A relapse of pneumothorax requiring a new chest tube occurred in two patients, their total duration of (both) drainages was 12 and 13 days respectively. The duration of drainage was not correlated to procedure characteristics such as the number or size of the biopsies, nor with age. There was a very significant correlation with TLC ( $\mathrm{p}=0.008$; fig. 2), but not with $\mathrm{DL}, \mathrm{CO}, \mathrm{Pa}_{\mathrm{a}} \mathrm{O}_{2}$ or $\mathrm{Pa}_{\mathrm{a}} \mathrm{CO}_{2}$. Duration of drainage was longer in patients with a low static compliance, though this correlation was not significant ( $\mathrm{p}=0.33$, nine patients only).

\section{Pathology}

For pathological analysis, a maximum of six (the most representative) tissue samples per patient were retained. The findings in these 118 samples are summarized in table 2. Their mean $\pm \mathrm{SD}$ (range) diameter was $3.95 \pm 1.23 \mathrm{~mm}$ (2.1-6.6). Figure 3 is a comparison between an open lung biopsy and a thoracoscopic biopsy.

Samples without coagulation artefacts were obtained in 20 patients and with only slight artefacts in three. Expressed per individual sample, coagulation artefacts were absent in $63 \%$ and slight in $23 \%$ of the samples.

Pleural tissue/interlobular septa and alveolated parenchyma were obtained in all patients, small precapillary arterioles in 21, and membranous bronchioles with accompanying pulmonary arteries in only 10. Expressed per individual sample, pleural tissue/interlobular septa and alveolated parenchyma were present in $78 \%$ of the specimens, small precapillary arterioles in 54\% and membranous bronchioles and accompanying pulmonary arteries in only $10 \%$.

Overall quality of the samples was rated as good in 23 patients and intermediate in one. Seventy- eight per cent of the samples were considered good, $14 \%$ intermediate and $8 \%$ poor

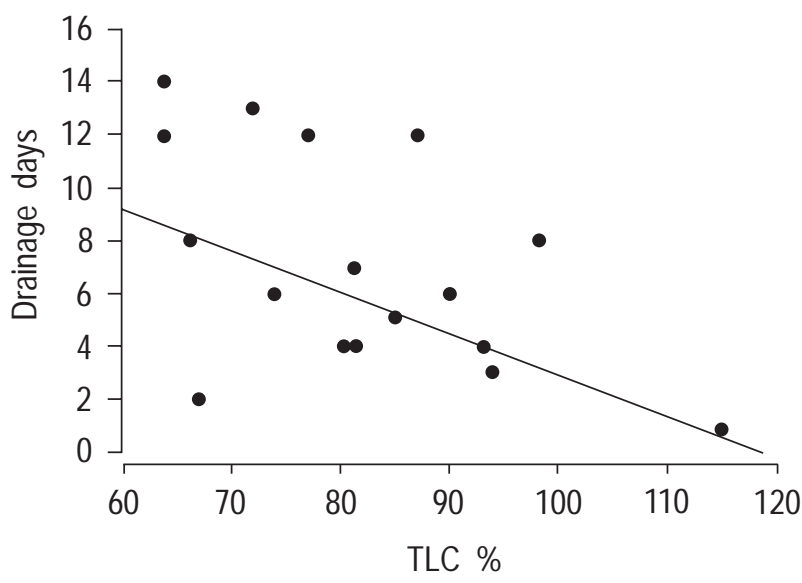

Fig. 2. - Relationship between pre-existing total lung capacity (TLC) (\% normal) and the duration of drainage in the 17 patients, in whom drainage lasted $\geq 1$ day. A significant correlation was found $(p=0.008)$.

\section{Final diagnosis}

The pathology report and the final conclusion according to the above mentioned four level classification are also summarized in table 1 .

In patients $1-6$, the biopsy material was diagnostic as such.

In patients $7-18$, biopsy findings were diagnostic if correlated with the clinical and CT findings. Confirmatory follow-up data are also presented in table 1. Pathology and suggestive findings on HRCT [17], together with exclusion of systemic disease, led to a diagnosis of idiopathic usual interstitial pneumonia in four patients. One was confirmed at autopsy, three had a compatible followup at 33, 26 and 16 months, respectively.

In patients 19-22, only a suggestion towards a group of diseases could be made. In two cases, a lymphocytic interstitial pneumonia (LIP) was found. Lymphoma, immunodeficiency or acquired immunodeficiency syndrome (AIDS) could be ruled out by the further clinical work-up. One case had an uneventful follow-up, the other patient died 10 months later despite immunosuppressive therapy. No autopsy was performed. In two patients, a pulmonary vascular problem was suggested by the pathologist. In one case with findings of thrombotic type pulmonary hypertension, the further clinical work-up by

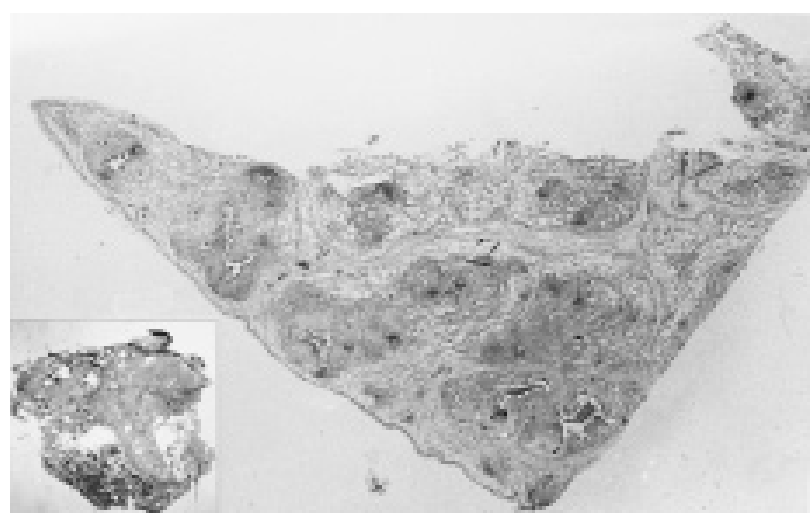

Fig. 3. - Masson's trichrome stain of a processed open lung biopsy and a thoracoscopic lung biopsy (inset). (Internal scale bar=1 cm). 
perfusion scintigraphy revealed the diagnosis of multiple pulmonary emboli. In the other very young patient, biopsy findings of alveolar haemorrhage were further explained in a renal biopsy with evidence of Wegener's disease.

Finally, in patients 23-24, the biopsies were of no diagnostic value at all. In one case with suggestive HRCT findings, a treatment with azathioprine and steroids was started for a presumptive UIP. PFT's remained stable since then. In the other, the reticular pattern on HRCT remained unexplained, PFT's were stable over 14 months, and no further measures were taken.

Based on the biopsy findings confronted with the existing clinical and HRCT data, a clinically relevant diagnosis could be made in 18 patients. In four patients, some diagnostic clues were present, but further examinations were needed.

In 15 patients, tissue samples taken from the upper (including middle on the right side) or lower lobes were sampled separately. In 10 samples, the same pathological findings were present in both lobes. In five patients, however, the ability to take several biopsies from different lobes proved to be important. In two patients, chronic interstitial pneumonitis of the usual type was diagnosed in one lobe, while end-stage fibrosis was found in the other. In three patients, the typical findings were present in one lobe, while biopsies from the other were normal: one case of sarcoidosis (upper lobe only), one case of carcinomatous lymphangitis (lower lobe only) and one case of end-stage fibrosis (lower lobe only).

\section{Discussion}

The quality and diagnostic value of 118 MTLB samples from 24 patients with ILD was studied. A diagnosis could be made in 18 patients, and the disease could be further classified in four. No major complications occurred, but prolonged chest tube drainage, depending on the severity of the underlying disease, was a problem in some patients. The ability to take several biopsies from different lobes proved to be useful in one third of the cases.

Simple rigid thoracoscopy has been safely and effectively performed by well trained pulmonologists for several decades $[1,2]$. The recent introduction of modern video-equipment and more refined instrumentation expanded the indications to diffuse and localized pulmonary diseases, sympathectomy for hyperhydrosis, mediastinal tumours and pericardial disease [3]. Despite encouraging reports in the literature from the 1980s on MTLB in ILD $[9,10]$, most pulmonologists did not use MTLB in the diagnostic work-up of ILD. Many pulmonologists probably still fear the complications of thoracoscopy, while many pathologists still have to become acquainted with the smaller amount of tissue compared to the larger surgical samples.

Previous studies on MTLB with diathermy coagulation forceps did not specifically address the issue of biopsy quality. Boutin et al. [9] reported on MTLB in 20 patients with diffuse ILD. Up to eight biopsies were taken, and a diagnosis was obtained in all 20. The number of "more readily" made diagnoses such as pneumoconiosis, sarcoidosis or carcinomatous lymphangitis, however, was high (10 of 20). DiJkman et al. [10] reported on this procedure in 63 patients. A conclusive result was found in 57 (90\%) patients. Thirty per cent of the patients had either pneumoconiosis, sarcoidosis or carcinomatous lymphangitis. In the present series, a diagnosis could be made in 18 of $24(75 \%)$ patients, while the disease could be further classified in another four (17\%). The number of patients with either pneumoconiosis, sarcoidosis or carcinomatous lymphangitis was only three (12\%). Useful specimens were obtained in all patients, and in $92 \%$ of the 118 samples. The mean diameter of the biopsies was $3.95 \mathrm{~mm}$ (range 2.1-6.6), and thus much larger than for TBB.

More detailed analysis of the samples in this study revealed that coagulation artefacts were not a major problem (only $14 \%$ of the samples). As already stated by Boutin et al. [9], it is important to keep coagulation time as short as $1-2 \mathrm{~s}$ to avoid artefacts.

The diagnostic accuracy of specimens for ILD depends on: 1) the distribution pattern of the interstitial disease, and thus the lobular compartment involved, and 2) the histological specificity of the disease.

Considering the distribution pattern, pleural tissue/ interlobular septa and alveolated parenchyma were present in sufficient quantity in all patients and in $78 \%$ of the MTLB samples. Consequently, diagnoses such as chronic interstitial pneumonitis of the usual or desquamative type, or end-stage lung fibrosis could be made with confidence. These diseases have a low morphological specificity, but are characterized by a widespread involvement particularly of the alveolar compartment [18].

Small precapillary arterioles were obtained in 21 patients (54\% of the samples) and central pulmonary arteries in 10 patients $(10 \%$ of the samples). It has been previously mentioned that suspected pulmonary vasculitis or other pulmonary vascular disorders are poor indicators for MTLB. In the series of DiJKMAN et al. [10], a diagnosis of vascular disorders was possible in three of six occurrences. In the current data, a final diagnosis (primary pulmonary hypertension in a young female and Wegener's disease in a middle-aged male) was possible in two instances, in two other patients, a renal biopsy for the diagnosis of Wegener's disease or vascular studies for the diagnosis of pulmonary microemboli were needed. Although less powerful, the technique of MTLB thus remains useful in suspected vascular pathology, especially if there are lesions in the smaller pulmonary arterioles.

Membranous bronchioli were present in only 10 patients (10\% of the samples). Predominantly central lesions such as bronchiolitis obliterans with organising pneumonia (BOOP) will probably remain a difficult challenge for the MTLB technique, although this diagnosis could be substantiated in one of the patients based on MTLB and clinical findings.

Secondly, the histopathological specificity of ILD biopsy samples is high in cases of vascular changes associated with hypertension, infections such as Pneumocystis carinii pneumonia (PCP), sarcoidosis, carcinomatous lymphangitis, hypersensitivity pneumonitis, noninfectious granulomatous diseases such as Wegener's, amyloid deposition, histiocytosis X, eosinophilic pneumonia, alveolar proteinosis or lymphangioleiomyomatosis [19]. Table 1 illustrates that the latter conditions are also diagnostic in our MTLB samples (cases 1-6), but with lower diagnostic accuracy in vascular diseases, where clinicopathological confrontation is warranted to upgrade the histopathological findings (cases 8 and 16). 
Sampling of biopsies from the upper and lower lobe separately proved to be useful for staging UIP in two patients, since pathognomonic findings were present in one lobe, while end-stage fibrosis was found in the other. In three patients, the diagnostic findings were present in one lobe only. The possibility of multiple sampling is an important advantage of MTLB over OLB. It is well known that ILD does not have a uniform spread throughout the whole lung. VAMT gives the unique opportunity to inspect the whole lung, choose the biopsy areas carefully and take biopsies from several lobes.

No major complications such as important bleeding or persistent fistula occurred in this series. The procedure did not cause temporary respiratory insufficiency. There is, however, a possible bias towards referral of patients with a less compromised pulmonary function for this new technique. Some patients nonetheless had a poor lung function, with a $D \mathrm{~L}, \mathrm{CO}$ as low as $28 \%$ predicted, $\mathrm{Pa}, \mathrm{O}_{2}$ as low as $4.9 \mathrm{kPa}, \mathrm{Pa}_{\mathrm{a}} \mathrm{CO}_{2}$ as high as $8 \mathrm{kPa}$ or a moderately elevated $P$ ap (up to $43 \mathrm{mmHg}$ ).

Prolonged air-leak was the most troublesome problem (mean duration of drainage 5.3 days). This was not correlated to the number or size of the biopsies, but to the TLC $(p=0.008)$ and static compliance (not significant, possibly due to the small numbers of patients with this measurement).

In the series of Boutin et al. [9], a prolonged air-leak ( $>5$ days) was noted in three of 20 patients with stiff lungs and fibrosis. In the series of DiJKman et al. [10], the mean duration of drainage was 4.5 days (maximum 14), and pneumothorax persisting over 1 week was mainly seen in patients with low compliance. The use of extra coagulation after sampling might help to reduce this complication in the future. In some patients, however, the days spent in the pulmonary ward were useful to start and monitor specific therapy.

Based on this and other series, MTLB can be an interesting second choice for interventional pulmonologists in a variety of ILD if TBB or BAL have failed to provide a diagnosis. The technique has some advantages over a surgical biopsy, which can be reserved as the final step in many instances. The possibility to take several biopsies from different sites under visual guidance, and the lower morbidity are the most important advantages. Nonetheless, to allow a sensible and safe use of MTLB, some important limitations should be kept in mind. A smaller diagnostic sensitivity must be expected in diseases where central airways, and to a lesser extent pulmonary arteries, are of fundamental importance for the pathologist's diagnosis. A prolonged air-leak is to be anticipated in patients with very stiff or honeycombing lungs, where VATS with a stapler or OLB with a suture may be a reasonable alternative [11]. Both MTLB and VATS should be avoided in case of suspected major pleural adhesions, in severe pulmonary hypertension and in very sick ventilated patients, in whom OLB carries less risk [7].

In conclusion, this and other series illustrate that medical thoracoscopy with lung biopsy is an effective and safe procedure in the hands of well trained interventional pulmonologists. Depending on institutional habits and local expertise, it can be an interesting, and probably less expensive, alternative to video-assisted thoracoscopic surgery wedge biopsy in diagnostic work-up of interstitial lung disease.

\section{References}

1. Oldenburg FA, Newhouse MT. Thoracoscopy. A safe, accurate diagnostic procedure using the rigid thoracoscope and local anesthesia. Chest 1979; 75: 45-50.

2. Viskum K, Enk B. Complications of thoracoscopy. Poumon Coeur 1981; 37: 25-28.

3. Loddenkemper R, Boutin C. Thoracoscopy: present diagnostic and therapeutic indications. Eur Respir $J$ 1993; 6: 1544-1555.

4. Mathur PN, Astoul P, Boutin C. Medical thoracoscopy. Technical details. Clin Chest Med 1995; 16: 479-486.

5. Mathur PN, Loddenkemper R. Medical thoracoscopy. Role in pleural and lung diseases. Clin Chest Med 1995; 16: 487-496.

6. Harris RJ, Kavuru MS, Rice TW, Kirby TJ. The diagnostic and therapeutic utility of thoracoscopy. A review. Chest 1995; 108: 828-841.

7. Coosemans W, Lerut TE, Van Raemdonck DE. Thoracoscopic surgery: The Belgian experience. Ann Thorac Surg 1993; 56: 721-730.

8. Raghu G. Interstitial lung disease: a diagnostic approach. Are CT scan and lung biopsy indicated in every patient? Am J Respir Crit Care Med 1995; 151: 909-914.

9. Boutin C, Viallat JR, Cargnino P, Rey F. Thoracoscopic lung biopsy. Experimental and clinical preliminary study. Chest 1982; 82: 44-48.

10. Dijkman JH, van der Meer JW, Bakker W, Wever AM, van der Broek PJ. Transpleural lung biopsy by the thoracoscopic route in patients with diffuse interstitial pulmonary disease. Chest 1982; 82: 76-83.

11. Molin LJ, Steinberg JB, Lanza LA. VATS increases costs in patients undergoing lung biopsy for interstitial lung disease. Ann Thorac Surg 1994; 58: 1595-1598.

12. Bensard DD, McIntyre RC, Waring BJ, Simon JS. Comparison of video thoracoscopic lung biopsy to open lung biopsy in the diagnosis of interstitial lung disease. Chest 1993; 103: 765-770.

13. Boutin C, Viallat J, Cargnino P, Farisse P. Thoracoscopy in malignant pleural effusions. Am Rev Respir Dis 1981; 124: $588-592$.

14. Boutin C, Loddenkemper R, Astoul P. Diagnostic and therapeutic thoracoscopy: techniques and indications in pulmonary medicine. Tubercle and lung disease 1993; 74: 225-239.

15. Crystal RG, Gadek JE, Ferrans VJ, Fulmer JD, Line BR, Hunninghake GW. Interstitial lung disease: current concepts of pathogenesis, staging and therapy. $\mathrm{Am} \mathrm{J}$ Med 1981; 70: 542-568.

16. Katzenstein AL, Myers JL. Idiopathic pulmonary fibrosis: clinical relevance of pathologic classification. Am J Respir Crit Care Med 1998; 157: 1301-1315.

17. Douglas WW, Ryu JH, Swensen SJ, et al. Colchicine versus prednisone in the treatment of idiopathic pulmonary fibrosis. Am J Respir Crit Care Med 1998; 158: 220-225.

18. Carrington CB, Gacnsler EA, Coutu RE, FitzGerald MX, Gupta RG. Natural history and treated course of usual and desquamative interstitial pneumonia. N Engl J Med 1978; 298: 801-809.

19. Churg A. Biopsy: Handling and diagnostic limitations. In: Thurlbeck W, ed. Pathology of the lung. Stuttgart: Georg Thieme Verlag, 1987. 